\title{
Erratum to: Intraoperative Tumor Detection Using a Ratiometric Activatable Fluorescent Peptide: A First-in-Human Phase 1 Study
}

\author{
Jonathan T. Unkart, MD, MS ${ }^{1}$, Steven L. Chen, MD, MBA ${ }^{2}$, Irene L. Wapnir, MD², Jesús E. González, PhD ${ }^{2}$, \\ Alec Harootunian, $\mathbf{P h D}^{2}$, and Anne M. Wallace, $\mathbf{M D}^{1}$ \\ ${ }^{1}$ Department of Surgery, Moores Cancer Center, University of California, San Diego, La Jolla, CA; ${ }^{2}$ Avelas Biosciences, \\ Inc., La Jolla, CA; ${ }^{3}$ Department of Surgery, Stanford University, Stanford, CA
}

ERRATUM TO: ANN SURG ONCOL

DOI 10.1245/S10434-017-5991-3

In the original article there is an error in Fig. 3. Following is the corrected Fig. 3.

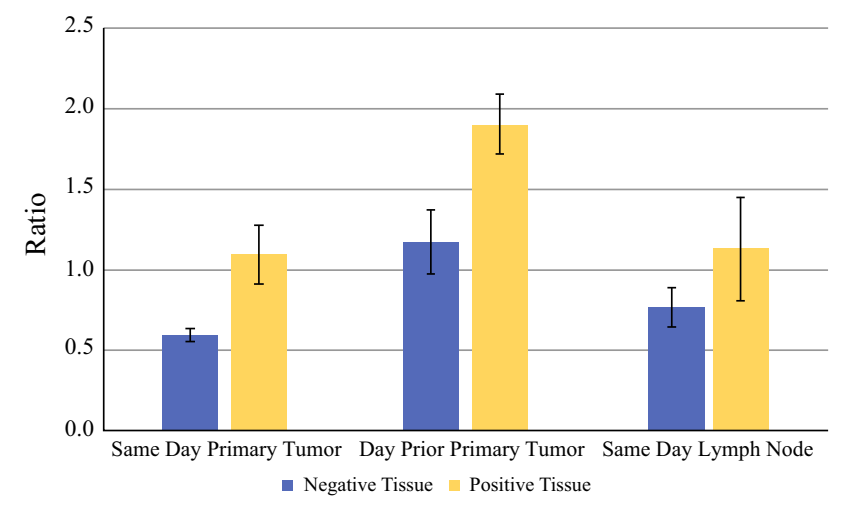

FIG. 3 Tissue ratio of malignant versus negative tissue. Average $\mathrm{Cy} 5 / \mathrm{Cy} 7$ ratio measurements from region of interest (ROI) versus non-malignant adjacent tissue are shown. The error bars represent standard deviations

The online version of the original article can be found under doi:10. 1245/s10434-017-5991-3.

(C) Society of Surgical Oncology 2017

Published Online: 31 July 2017

A. M. Wallace, MD

e-mail: amwallace@ucsd.edu 